\title{
Atividade antimicrobiana do extrato bruto etanólico de raízes e partes aéreas de Ottonia martiana Miq. (Piperaceae)
}

\author{
Cunico, M. M.'; Carvalho, J. L. S.'; Kerber, V. A. ${ }^{1}$; Higaskino, C. E. K. ${ }^{2}$; Cruz \\ Almeida, S. C. ${ }^{2}$; Miguel, M. D. ${ }^{1}$; Miguel, O. G. ${ }^{{ }^{*}}$ \\ 'Laboratório de Fitoquímica, Departamento de Farmácia, \\ Universidade Federal do Paraná, Curitiba, PR; \\ ${ }^{2}$ TECPAR, Curitiba, PR
}

Recebido para publicação em: 30/09/2003 Aceito para publicação em: 30/04/2004

\begin{abstract}
RESUMO: Ottonia martiana Miq., Piperaceae, conhecida na medicina popular brasileira como "anestésia", é um arbusto característico da Floresta Attântica. Devido à ação anestésica sobre a mucosa oral, raízes e partes aéreas são popularmente utilizadas em dores de dente, na forma de alcoolaturas (bochechos) ou pela mastigação de fragmentos de partes da planta. Como os microrganismos estão adquirindo resistência aos antibióticos tradicionais, a procura por novos agentes antimicrobianos, a partir de plantas, vem sendo intensificada. Nesta perspectiva, avaliou-se o efeito antimicrobiano do extrato bruto etanólico dos órgãos totais desta espécie (EBEtOH) frente às bactérias Enterococcus faecium (ATCC 6569), Enterobacter aerogenes (ATCC 13048) e Pseudomonas aeruginosa (ATCC 15442), utilizando-se os métodos de difusão em ágar e bioautografia. Os resultados obtidos por difusão em ágar mostraram que o EBEtOH de O. martiana apresenta potencial antibacteriano contra $E$. faecium, evidenciado pelo aparecimento de zonas de inibição de crescimento no respectivo bioautograma e não demonstraram ação antimicrobiana contra as outras cepas testadas.
\end{abstract}

Unitermos: Ottonia martiana; Enterococcus faecium; Enterobacter aerogenes; Pseudomonas aeruginosa; bioautografia.

ABSTRACT: Antimicrobial activity of crude ethanolic extracts of Ottonia martiana Miq. (Piperaceae) roots and aerial parts. Ottonia martiana Miq., Piperaceae, known in Brazilian folk medicine as "anestésia", is an herbaceous shrub found in Atlantic Tropical Forest. Due to its anesthetic action on the mucous membranes of the mouth, roots and aerial parts are commonly used to relief toothache, usually as alcoholic macerates (mouth washing) or by chewing parts of the plant. As most microorganisms are acquiring resistance to traditional antibiotics, the search for new antimicrobials agents, specially from plants, is being intensified. Based on this, the activity of the crude ethanolic extract from roots and aerial parts (EBEtOH) of $O$. martiana against Enterococcus faecium (ATCC 6569), Enterobacter aerogenes (ATCC 13048) and Pseudomonas aeruginosa (ATCC 15442) was 
evaluated using the agar difusion and bioautographic methods. Results from the agar diffusion assay showed that $O$. martiana EBEtOH has a potencial effect against $E$. faecium, which was corroborated by the presence of inhibition zones in the bioautographic test, whereas no inhibitory action against the other assayed bacteria was observed.

Key words: Ottonia martiana; Enterococcus faecium; Enterobacter aerogenes; Pseudomonas aeruginosa; bioautography.

\section{INTRODUÇÃO}

Ao longo das últimas décadas, desde a descoberta das penicilinas naturais, o avanço da indústria farmacêutica levou ao surgimento de diversos antimicrobianos, com espectro de ação cada vez mais amplo. Entretanto, a exposição aos antimicrobianos desencadeou resistência bacteriana, limitando as opções terapêuticas dos processos infecciosos.

Nesta ótica remete-se à questão das infecções hospitalares (nosocomiais), assunto polêmico e atual em nossos dias (MARINELL et al., 1997).

Dentre os microrganismos relacionados a infecções nosocomiais encontra-se o Enterococcus faecium, microrganismo encontrado principalmente no trato gastrointestinal e com menor freqüência na cavidade oral, vesícula biliar, uretra e vagina. Embora ainda existam controvérsias a respeito da virulência dos enterococos, estes patógenos são importantes em endocardite infecciosa, bacteremia, infecções do trato urinário, infecção de ferida cirúrgica e sepse neonatal (DUPRÈ et al., 2003).

A Pseudomonas aeruginosa, bactéria oportunista e associada a uma variedade de infecções em indivíduos debilitados, é um dos principais agentes isolados em casos de infecção hospitalar em uma unidade de terapia intensiva, particularmente em pneumonia associada à ventilação mecânica, pelo fato de adquirir resistência múltipla aos antibióticos usuais. Esse microrganismo pode causar infecções urinárias e respiratórias, pneumonias, meningites, endocardites e diversos outros tipos de infecção (ARRUDA, 1998; FOCA et al., 2000).

Outra bactéria associada à infecção nosocomial é a Enterobacter aerogenes, a qual pode causar doenças associadas à bacteremia e síndrome séptica em vários locais, principalmente nos tratos urinários e respiratórios (BRAGA RABELLO et al., 2001).

A resistência a agentes antimicrobianos é grave e preocupante e requer não somente a pesquisa para o desenvolvimento de novas substâncias antimicrobianas, mas também o desenvolvimento de novas abordagens para o tratamento de infecções bacterianas.

Logo, a busca de propriedades antibacterianas de extratos de plantas e de substâncias mais específicas tem sido incentivada e intensificada (MIGUEL;MIGUEL, 1999).

Sendo assim, entre inúmeras espécies vegetais a serem investigadas destaca-se a Ottonia martiana Miq., pertencente à família Piperaceae, que apresenta em sua composição química uma grande diversidade de metabólitos secundários bioativos, dentre eles, as amidas, de grande interesse medicinal (SENGUPTA; RAY, 1987).

O. martiana, arbusto da Floresta Atlântica (YUNCKER, 1973), é empregada popularmente no tratamento de odontalgias. É conhecida como "anestésia" pelos nativos do litoral paranaense devido à sua ação anestésica sobre a mucosa bucal (LOPES, 1989; CUNICO, 2001).

Esta espécie vegetal apresenta em sua composição química a piperlonguminina, isopiperlonguminina e a piperovatina, amidas isoladas e identificadas em estudos fitoquímicos realizados por Lopes (1989) e Cunico (2001).

Rev. Bras. Farmacogn., V. 14, n. 2, jul.-dez. 2004. 
Apesar destas amidas serem previamente conhecidas, pouco se conhece sobre as suas atividades biológicas, das quais destacam-se os efeitos da piperovatina, tais como salivação, dormência e sensação de queimadura na língua, além da ação piscicida (MAKAPUGAY et al., 1983; MACFERREN ; RODRIGUEZ, 1998), e atividade inseticida, causada pela piperlonguminina (SÁEZ et al.,1998).

Em relação ao extrato etanólico bruto de raízes e caules de 0 . martiana estudos demonstraram que esta espécie vegetal apresenta potencial antimicrobiano frente a Staphylococcus aureus e aos fitopatógenos Fusarium oxysporum, Colletotrichum acutatum e Rhizoctonia sp. (CUNICO, 2001; CUNICO et al.,2003).

Diante das considerações expostas, a realização de uma investigação da atividade antimicrobiana do extrato bruto etanólico das raízes e partes aéreas de $O$. martiana Miq. frente a alguns microrganismos relacionados à infecções nosocomiais é justificada.

\section{MATERIAL E MÉTODOS}

\section{Material vegetal}

Raízes e partes aéreas de Ottonia martiana Miq., foram coletadas em fevereiro de 2002, no Município de Guaratuba, Coroados (encosta da Floresta Atlântica - Serra do Mar), no Estado do Paraná, a uma altitude de 20 metros.

A identificação da espécie botânica foi realizada pelo Dr. Gerdt Hatschbach do Museu Botânico Municipal (MBM) da Prefeitura de Curitiba, Paraná, e uma exsicata da espécie encontrase depositada no Herbário deste Museu, sob no 259.057.

\section{Preparação do extrato bruto}

O material coletado (raízes e partes aéreas) foi submetido à secagem em estufa com tiragem de ar úmido, à temperatura de $40^{\circ} \mathrm{C}$ durante 48 horas para estabilização $(\sim 10 \%$ de umidade), e conservado ao abrigo de luz e umidade.

Em seguida, $700 \mathrm{~g}$ da droga vegetal foram maceradas durante 7 dias, com etanol a 95\% (700 g/2 L), por três vezes. Após filtração, o extrato foi concentrado em evaporador rotatório sob pressão reduzida $\left(40^{\circ} \mathrm{C}\right)$ para aproximadamente $1 / 5$ do seu volume, armazenado em frasco âmbar e conservado em freezer por um período de 24 horas, para precipitação de pigmentos. A partir da filtração a vácuo, o Extrato Bruto Etanólico das Raízes e Partes Aéreas (EBEtOH) foi obtido.

\section{Ensaio biológico}

Foram utilizados no teste para o potencial antimicrobiano do EBEtOH de O. martiana, os métodos de difusão em ágar de Kirby-Bauer e bioautografia (WELTZIEN, 1958), com as modificações propostas por Romeiro (2001), buscando-se encontrar alguma atividade inibitória do desenvolvimento das bactérias Enterococcus faecium (ATCC 6569), Enterobacter aerogenes (ATCC 13048) e Pseudomonas aeruginosa (ATCC 15442).

As cepas, fornecidas pelo Tecpar, foram repicadas em meio Plate Count Agar (PCA) e incubadas à $35^{\circ} \mathrm{C}, 24$ horas antes do teste. Para o preparo do inóculo, as culturas jovens de cada bactéria foram padronizadas em salina estéril segundo a escala 0,5 de MacFarland.

Alíquotas de $1 \mathrm{~mL}$ de cada suspensão padronizada foram adicionadas a $100 \mathrm{~mL}$ de PCA fundido, à temperatura de $45^{\circ} \mathrm{C}$, e $10 \mathrm{~mL}$ de meio inoculado foram transferidos para a superfície 
de meio PCA solidificado (60 mL). Discos de papel estéreis foram respectivamente impregnados com $10 \mathrm{~mL}$ de etanol, $10 \mathrm{~mL}$ de EBEtOH $(32,9 \mathrm{mg} / \mathrm{mL})$, e $10 \mu \mathrm{L}$ de solução de cloranfenicol em etanol (3 $\mathrm{mg} / \mathrm{mL}$ - Newprov), e distribuídos sobre a superfície do meio inoculado. O teste foi realizado em duplicata. As placas foram incubadas em estufa, à $35^{\circ} \mathrm{C}$, durante 24 horas. Passado este período, as placas foram retiradas da estufa e medidos os halos de inibição, quando presentes.

Para a realização do teste de bioautografia, a suspensão bacteriana foi padronizada em salina segundo a escala 0,5 de MacFarland.

Volumes de $3 \mu \mathrm{L}$ do $\mathrm{EBEtOH}(32,9 \mathrm{mg} / \mathrm{mL})$ e das substâncias piperovatina $(0,1 \mathrm{mg} / \mathrm{mL}$ em etanol), piperlonguminina $(0,1 \mathrm{mg} / \mathrm{mL}$ em etanol) e isopiperlonguminina $(0,1 \mathrm{mg} / \mathrm{mL}$ em etanol) foram aplicados sobre placas de sílica gel $\mathrm{GF}_{254}(2,5 \times 5,0 \mathrm{~cm})$ as quais foram submetidas ao sistema eluente n-hexano:acetato de etila (70:30). Após secagem, as placas cromatografadas foram colocadas em uma placa de Petri e sobre elas verteu-se o meio de cultura PCA contendo as suspensões bacterianas previamente padronizadas e o revelador cloreto de trifeniltetrazolium (1\%). Em seguida, as mesmas foram incubadas à $35^{\circ} \mathrm{C}$. Após nítido crescimento dos microrganismos (24 h), a ocorrência ou não, de halos de inibição foi observado. O teste foi realizado em duplicata. Como controle positivo, foram utilizados $10 \mu \mathrm{L}$ de solução de cloranfenicol em etanol (3 mg/mL).

\section{RESULTADOS E DISCUSSÃO}

O ensaio de atividade antibacteriana por difusão em ágar permitiu evidenciar a atividade do EBEtOH de O. martiana frente a E. faecium. Contra as cepas Gram negativas testadas, não foram observados halos de inibição (Tabela 1).

Tabela 1. Medida dos halos de inibição $(\mathrm{mm})$ dos extratos brutos etanólicos (EBEtOH) das raízes e partes aéreas de Ottonia martiana contra Enterococcus faecium (ATCC 6569), Enterobacter aerogenes (ATCC 13048) e Pseudomonas aeruginosa (ATCC 15442).

\begin{tabular}{|c|c|c|c|}
\hline & \multicolumn{3}{|c|}{ Halo de inibição (mm) } \\
\cline { 2 - 4 } & $\begin{array}{c}\text { E. faecium } \\
(\text { Gram }+)\end{array}$ & $\begin{array}{c}\text { E. aerogenes } \\
(\text { Gram }-)\end{array}$ & $\begin{array}{c}\text { P. aeruginosa } \\
\text { (Gram -) }\end{array}$ \\
\hline $\begin{array}{c}\text { EBEtOH } \\
(\mathbf{0 , 3 2 9} \mathbf{~ m g})\end{array}$ & 4 & 0 & 0 \\
\hline $\begin{array}{c}\text { Controle Cloranfenicol } \\
(\mathbf{0 , 0 3 0} \mathbf{~ m g})\end{array}$ & 9 & 7 & 2 \\
\hline \begin{tabular}{c} 
Crescimento bacteriano \\
\hline
\end{tabular} & + & + & + \\
\hline
\end{tabular}

Resultados expressos em mm (diâmetro dos halos de inibição) + Crescimento bacteriano

Por apresentar limitações para substâncias com baixa difusibilidade no meio de cultura, o método de difusão em ágar foi utilizado somente como teste preliminar qualitativo. A fim de confirmar os resultados obtidos no ensaio por difusão em ágar, empregou-se outro método de detecção de atividade antibacteriana, a bioautografia, um método simples, rápido, confiável e conveniente para testar os efeitos antimicrobianos de extratos de plantas e de substâncias puras, e que pode direcionar o isolamento dos constituintes bioativos (HOSTETTMANN, 1998). 
Os resultados obtidos no ensaio por bioautografia indicaram a presença de substâncias bioativas no $\mathrm{EBEtOH}$ de $O$. martiana frente a $E$. faecium, devido à presença de 2 zonas de inibição de crescimento bacteriano, com os respectivos $\mathrm{R} f$ de 0,76 e 0,86 (Tabela 2).

Nos ensaios com $E$. aerogenes e $P$. aeruginosa não se observaram zonas de inibição de crescimento microbiano, confirmando, desta forma, os resultados obtidos no ensaio por difusão em ágar.

Os valores de $\mathrm{R} f$ das zonas de inibição de crescimento obtidos neste ensaio não foram coincidentes com aqueles das amidas isoladas desta espécie vegetal (fração diclorometano), indicando que a piperovatina (1), piperlonguminina (2) e isopiperlonguminina (3) não são as substâncias responsáveis pela atividade antimicrobiana detectada (Tabela 2).

Tabela 2. Valores de $\mathrm{R} f$ das isobutilamidas isoladas de Ottonia martiana e das zonas de inibição de crescimento bacteriano no bioautograma obtido para o extrato etanólico bruto de raízes e partes aéreas da espécie frente a Enterococcus faecium (ATCC 6569).

\begin{tabular}{c|c}
\hline \multicolumn{1}{|c|}{} & $\begin{array}{c}\text { Valores de Rf } \\
\text {-hexano:acetato de etila } \\
(70: 30)\end{array}$ \\
\hline EBEtOH & 0,76 e 0,86 \\
Piperovatina \\
$\begin{array}{c}\text { (1) } \\
\text { Piperlonguminina } \\
(\mathbf{2}) \\
\text { Isopiperlonguminina } \\
(\mathbf{3})\end{array}$ & 0,35 \\
\hline
\end{tabular}<smiles>COc1ccc(C/C=C/C=C/C(=O)NCC(C)C)cc1</smiles>

(2) trans-2-trans-4

(3) $c i s-2-c i s-4$

Estudo anterior realizado com $3 \mu \mathrm{L}$ de extrato etanólico bruto de raízes e caules de 0 . martiana $(20,5 \mathrm{mg} / \mathrm{mL})$ frente a 2 bactérias presentes na mucosa oral permitiu evidenciar um potencial antibacteriano contra Staphylococcus aureus (CUNICO et al., 2003), equivalente ao potencial verificado no ensaio frente a $E$. faecium. Visando isolar e identificar as substâncias responsáveis por esta bioatividade, novos ensaios estão sendo realizados.

Estudos similares foram realizados com extratos etanólicos de diversas plantas medicinais (alecrim-pimenta, cravo, alecrim, pimenta-da-jamaica, sálvia, calêndula, entre outras). Os 
resultados obtidos, apesar de modestos, comprovaram o potencial antimicrobiano da sálvia, alecrim e calêndula frente às bactérias Gram-positivas Staphylococcus aureus e Staphylococcus epidermidis, e exibiram o potencial antimicrobiano do cravo e alecrim-pimenta frente às bactérias Gram-negativas Escherichia coli e Salmonella thyphimurium demonstrando, desta forma, que extratos etanólicos de plantas apresentam perspectivas para a obtenção de antibióticos naturais (SOUZA et al., 1997; BARA; VANETTI, 1998; ULUBELEN et al., 2000; VOLPATO et al., 2001).

Logo, o potencial antimicrobiano exibido pelo EBEtOH da O. martiana frente a bactéria Gram-positiva E. faecium deve ser investigado com mais detalhes, a fim de contribuir para a descoberta e desenvolvimento de novos agentes antimicrobianos naturais, os quais, se viáveis, representarão alternativas terapêuticas aplicáveis no tratamento de processos infecciosos nosocomiais.

\section{CONCLUSÃO}

Os resultados obtidos na avaliação preliminar da atividade antibacteriana do EBEtOH de O. martiana demonstraram potencial antibacteriano sobre o crescimento de E. faecium e não exibiram ação antimicrobiana frente às outras bactérias testadas.

O teste de bioautografia confirmou os resultados obtidos pelo método de difusão em ágar e permitiu detectar substâncias responsáveis pela atividade antibacteriana do EBETOH de $O$. martiana.

Apesar do extrato de O. martiana apresentar potencial antibacteriano aparentemente modesto sobre o crescimento de E. faecium, há ainda muito a ser investigado, buscando-se isolar e identificar as substâncias responsáveis por esta atividade.

Por estas razões, estudos complementares estão sendo realizados, pela avaliação do EBEtOH e substâncias isoladas em outras concentrações, meios e métodos, já que o de difusão em ágar é utilizado apenas como teste preliminar, devido à sua limitação para compostos com baixa difusibilidade no meio de cultura.

\section{AGRADECIMENTOS}

Ao Dr. Gerdt Hatschbach do Museu Botânico Municipal da Prefeitura de Curitiba (MBM), pela identificação da espécie vegetal; ao coletor Osmar S. Ribas do MBM (nํ3633), pela obtenção do material vegetal estudado; e ao TECPAR-PR, pelo fornecimento das culturas puras de bactérias utilizadas neste trabalho.

\section{REFERÊNCIAS}

ARRUDA, E. A. G. Infecção hospitalar por Pseudomonas aeruginosa multi-resistente: análise epidemiológica no HC-FMUSP. Revista da Sociedade Brasileira de Medicina Tropical, v.31, n.5, p.503-504, 1998.

BARA, M. T. F.; VANETTI, M. C. D. Estudo da atividade antibacteriana de plantas medicinais, aromáticas e corantes naturais. Revista Brasileira de Farmacognosia, v.7/8, n.1/2 , p.21-34, 1998.

BRAGA RABELLO, S.; GODOY, C. V. C.; SANTOS, F. R. W. Presença de bactérias em instrumentais e superfícies do ambiente clínico odontológico. Revista Brasileira de Odontologia, v.58, n.3, 2001.

CUNICO, M. M.. Estudo fitoquímico e das atividades antimicrobianas da Ottonia martiana Miq. - Piperaceae. Curitiba, 83f. Dissertação (Mestrado em Ciências Farmacêuticas) - Setor de Ciências da Saúde, Universidade Federal do Paraná, 2001.

Rev. Bras. Farmacogn., V. 14, n. 2, jul.-dez. 2004. 
CUNICO, M. M.; MIGUEL, O. G.; MIGUEL, M. D.; KERBER, V. A.; MONTRUCCHIO, D. P.; AUER, C. G.; GRIGOLETTI JÚNIOR, A. Avaliação da atividade antibacteriana de Ottonia martiana Miq., Piperaceae. Revista de Ciências Farmacêuticas, v.24, n.2, p.141-145, 2003.

DUPRÈ, I.; ZANETTI, S.; SCHITO, A. M.; FADDA; G.; SECHI; L. A. Incidence of virulence determinants in clinical Enterococcus faecium and Enterococcus faecalis isolates collected in Sardinia (Italy). Journal of Medical Microbiology, v.52, p.491-498, 2003).

FOCA, M.; JAKOB, K.; WHITTIER, S. Infecção endêmica por Pseudomonas aeruginosa em Unidade de Cuidados Intensivos Neonatal. New England Journal of Medicine, n.343, p.695-700, 2000.

HOSTETTMANN, K. Strategy for the biological and chemical evaluation of plant extracts. Pure and Applied Chemistry, v.70, n.11, p.23-27, 1998.

LOPES, M. Contribuição para o estudo fitoquímico de Ottonia martiana Miq. - Piperaceae. Curitiba, $102 f$. Dissertação (Mestrado em Botânica) - Setor de Ciências Biológicas, Universidade Federal do Paraná, 1989.

MACFERREN, M. A.; RODRIGUEZ, E. Piscicidal properties of piperovatine from Piper piscatorum. Journal of Ethnopharmacology, v.60, p.183-187, 1998.

MAKAPUGAY, H.; SOEJARTO, D. D.; KINGHORN, A. D.; BORDAS, E. Piperovatine, the tongue-numbing principle of Ottonia frutencens. Journal of Ethnopharmacology, v.7, p.235-238, Mar., 1983.

MARINELL, M.; PIERSON, C.; CHENOWETH, C. The stethoscope: a potencial source of nosocomial infection? Archives of Internal Medicine, v.157, p.786-790, 1997.

MIGUEL, M. D.; MIGUEL, O. G. Desenvolvimento de fitoterápicos. São Paulo: Robe, 1999.

ROMEIRO, R. da S. Métodos em bacteriologia de plantas. Viçosa: Ed. UFV, 2001.

SÁEZ, J.; GRANADOS, H.; ESCOBAR, G.; CARDONA, W.; ATEHORTUA, L.; CALLEJAS, R.; CORTES, D.; GONZALEZ, C. Piperlonguminina y estigmasterol, compuestos de raíces y tallos de Piper auritum, actividad insecticida de extractos. Revista Colombiana de Química, v.27, n.1, p.77-81, 1998.

SENGUPTA, S.; RAY, A. B. The chemistry of Piper species: a review. Fitoterapia, v.63, n.3, p.147-166, 1987.

SOUZA, G. H. B. Atividade antimicrobiana de óleos essenciais extraídos de plantas utilizadas na medicina popular brasileira. In: JORNADA FARMACÊUTICA DA UNESP, 44, 1997, Araraquara. Anais da 44a Jorn. Farmac. Araraquara, FCF/UNESP, 1997. p.63.

ULUBELEN, A.; ÖKSÜZ, S.; BOZOK-JOHANSSON, C.; CELIK, C.; VOELTER, W. Antibacterial Diterpenes from the Roots of Salvia viridis. Planta Medica, v.66, n.5, p.458-462, 2000.

VOLPATO, A. M. M.; RIOS, E. M.; MIGUEL, M. D.; SANDER, P. C.; MIGUEL, O. G. Investigação da atividade antibacteriana de Calendula officinalis L. (Asteraceae). Revista Visão Acadêmica, v.2, n.1, p.710, 2001.

WELTZIEN, H. C. Ein biologischer test für fungizide substanzen auf dem papierchromatogramm. Naturwissenschaften, v.45, p.288-289, 1958.

YUNCKER, T. C. The Piperaceae of Brazil. Hoehnea, v.3, p.121-138, 1973.

*Autor para correspondência:

Prof. Dr. Obtúlio G. Miguel

Laboratório de Fitoquímica

Depto. de Farmácia - UFPR

Av. Prefeito Lothário Meissner, n, 3400

CEP: 80210-170 - Curitiba, PR.

E-mail: obdulio@ufpr.br 